\title{
Evaluation of the mechanical properties of Douglas-fir and Japanese cedar lumber and its structural glulam by nondestructive techniques
}

\author{
Te-Hsin Yang ${ }^{\mathrm{a}}$, Song-Yung Wang ${ }^{\mathrm{a}}$, Cheng-Jung Lin ${ }^{\mathrm{b}}$, Ming-Jer Tsai ${ }^{\mathrm{a}, *}$ \\ a School of Forestry and Resource Conservation, College of Bioresource and Agriculture, National Taiwan University, Taipei, Taiwan, ROC \\ ${ }^{\mathrm{b}}$ Division of Forest Utilization, Taiwan Forestry Research Institute, Taipei, Taiwan, ROC
}

Received 13 March 2006; received in revised form 6 November 2006; accepted 20 November 2006

Available online 2 January 2007

\begin{abstract}
The objectives of this study were to investigate the effects of the configuration of the lamina on the bending properties of glulam made from Douglas-fir and Japanese cedar lumber. By using a visual grading method according to CNS 14631 and nondestructive evaluation techniques (including the ultrasonic wave technique, transverse vibration test and static bending test), lamina having both higher dynamic MOE and static MOE were chosen for the outside layers, in order to manufacture homogeneous and heterogeneous grade structural glulam lamina, with higher strength properties. The degrees of correlation, obtained from the different nondestructive testing methods, were then analyzed. The results indicated that the DMOEv, DMOEt and MOE values for both Douglas-fir and Japanese cedar lumber showed a decreasing order as follows: construction grade $>$ standard grade $>$ utility grade. It was also found that the transverse vibration test is a better nondestructive method of evaluating sawn lumber. The different configurations of the lamina within glulam can be used to fabricate glulams with different grades of bending strengths. The predicted values of glulam $E_{\mathrm{b}(\mathrm{sp})}$, were higher than those of the experimental values $E_{\mathrm{b}(\mathrm{sc})}$. Moreover, the value of $E_{\mathrm{b}(\mathrm{sc})}$ increased linearly with an increasing MOE of the outside layers of lamina $\left(e_{3}\right)$.

(C) 2006 Elsevier Ltd. All rights reserved.
\end{abstract}

Keywords: Glulam; Static bending test; Transverse vibrating method; Ultrasonic wave method; Visual grading

\section{Introduction}

Glued laminated timber (glulam) is an engineered wood product, which can bring the natural beauty of the source wood into full play during construction. Glulam is made from sawn lumber lamina, arranged in horizontal layers, using glue; various lengths can be joined together, using scarf or finger joints, to achieve the desired length. It can be constructed from small-diameter timber, which means that dependence on old growth trees, considered necessary to provide the high strength and large spans for architectural design, is a thing of the past. These glulams have been successfully used in North America and in Europe for some time.

\footnotetext{
* Corresponding author. Tel.: +8862 33664641; fax: +886223686335 E-mail address: tmj@ntu.edu.tw (M.-J. Tsai).
}

Because the mechanical properties and the modulus of elasticity (MOE) of wood have a mostly positive linear correlation, we often judge the strength properties of wood by testing the MOE, which includes both static and dynamic testing. In static testing, a dead load is brought to bear on a wood species to its elastic limit; the MOE is calculated via the relationship of carrying capacity to the deflection degree. Dynamic testing includes vibration testing, ultrasonic wave transmission timing and stress wave transmission timing methods $[1,2]$.

Visual inspection is a simple and convenient nondestructive evaluation method. Galligan et al. [3] pointed out that through the use of both visual inspection and machine stress rating (MSR) methods, a basic strength classification could be established for wood products. Different classification results arise from the use of different visual inspection standards, however, in the evaluation of wood products. 
The Douglas-fir and Japanese cedar lumber selected for this study was tested by visual inspection, ultrasonic wave timing, transverse vibration testing and static bending stress testing methods. The degree of correlation of the results, using these different nondestructive testing methods, was then discussed. In addition, the properties of the glulam made from both Douglas-fir and Japanese cedar sawn lumber, were investigated, using ultrasonic wave testing and static bending methods.

\section{Materials and methods}

\subsection{Grading of sawn lumber}

A total of 160 pieces of Douglas-fir sawn lumber (Pseudotsuga menzresii, wood density in air dried condition (ru): $\left.530 \mathrm{~kg} / \mathrm{m}^{3}\right)$ and 138 pieces of Japanese cedar sawn lumber (Cryptomeria japonica, wood density in air dried condition (ru): $520 \mathrm{~kg} / \mathrm{m}^{3}$ ), with dimensions of $3.8 \mathrm{~cm}$ thickness $\times 8.9 \mathrm{~cm}$ width $\times 360 \mathrm{~cm}$ length, were used for this study. After the two wood species of sawn lumber had been dried, their moisture content was measured as being between $12 \%$ and $13 \%$; the lumber was graded in accordance with the following methods.

According to the specifications for CNS14631 structural sawn lumber, used for platform construction, the laminas were visually classified as follows: (A) construction grade lumber; (B) standard grade lumber; and (C) utility grade lumber.

The ultrasonic wave transmission velocity test was carried out using Sylvatest equipment (with a frequency of $16 \mathrm{kHz}$; Swiss Products), to investigate the velocity of ultrasonic wave transmission $(V)$ and dynamic modulus of elasticity (DMOEv). The ultrasonic test required the placement of two piezoelectric transducers (the transmitting and receiving transducers) in contact with opposite ends, and the $V$ and $\mathrm{DMOEv}$ were calculated from the following formulas:

$V=L / T$ and

DMOEv $=V^{2} \times \rho ;$

where $V$ is the ultrasonic wave velocity in the direction parallel to the grain of the lumber, $L$ is the distance between the two transducers, $T$ is the propagation time of the pulse from the transmitting transducer to the receiving transducer, DMOEv is the dynamic modulus of elasticity in the direction parallel to the grain of lumber, and $\rho$ is the density based on the mass to volume ratio of the lumber.

The transverse vibration test was carried out using a Metriguard Model 340 Transverse Vibration Tester. The dynamic modulus of elasticity (DMOEt) was evaluated by measuring the transversal vibration from which the undamped natural frequency of each specimen was determined. The DMOEt of the lumber was calculated by the following equation:

$\mathrm{DMOEt}=\frac{f r^{2} \times W \times L^{3}}{6.63 \times I} ;$ where DMOEt is the modulus of elasticity determined by transverse vibration, $f r$ is the natural frequency $(\mathrm{Hz}), W$ is the weight of the lumber, $L$ is the span of lumber between supports, and $I$ is the moment of inertia.

The static bending test was conducted in accordance with the third-point loading method, and a Shimadzu type testing machine was used. The MOE was calculated from the load and deflection curve under proportional limits by the following formula:

$\mathrm{MOE}=\frac{P^{\prime} a\left(3 L^{2}-4 a^{2}\right)}{48 \delta I} ;$

where $P^{\prime}$ is the load at proportional limit, $a$ is the distance from the end support to the nearest load point $\left(a=\frac{L}{3}\right), L$ is the span of lumber between supports, $\delta$ is the midspan deflection, and $I$ is the moment of inertia.

\subsection{Manufacture and testing of glulam}

Higher strength laminas were placed on the top and bottom sides in order to manufacture a grade of structural glulam with higher strength properties [4]. In our study, a glue spread of $323 \mathrm{~g} / \mathrm{m}^{2}$ of resorcinal resin adhesive (RF), with a high frequency induction heating pressure, was used in the manufacture of glulam.

The transmission time of ultrasonic waves, passing through the glulam in a longitudinal direction, was determined using an ultrasonic wave velocity device (Sylvatest, $16 \mathrm{kHz}$ ); the difference in velocity of the ultrasonic wave transmission, between the lamina and the glulam, was investigated.

A three-point-loading static bending test was carried out, where the distance between the two loading points, and the distance between the right and left fulcrums, were the same. In a situation like this, the average loading speed should not exceed 14.7 MPa per minute. Modulus of elasticity $\left(E_{\mathrm{b}}\right)$ and modulus of rupture (MOR) were also calculated by the following formula:

$$
\begin{aligned}
& E_{\mathrm{b}}=\frac{P^{\prime} a\left(3 L^{2}-4 a^{2}\right)}{48 \delta I} \text { and } \\
& \mathrm{MOR}=\frac{P L}{b h^{2}} ;
\end{aligned}
$$

where $P^{\prime}$ is the load at proportional limit, $a$ is the distance from the end support to the nearest load point $\left(a=\frac{L}{3}\right), L$ is the span of lumber between supports, $\delta$ is the midspan deflection, $P$ is maximum load, $b$ is the width of lumber, $h$ is the depth of lumber, and $I$ is the moment of inertia.

\section{Results and discussion}

\subsection{Correlation analysis of visual grading and $M O E$}

According to the specifications for CNS14631 structural sawn lumber, used in platform construction, the Douglasfir sawn lumber was graded as shown in Table 1. The grading results for Douglas-fir sawn lumber were as follows: (A) 
Table 1

Visual grading results of Douglas-fir and Japanese cedar lumber according to CNS 14631 and analysis of MOE values by ANOVA

\begin{tabular}{|c|c|c|c|c|c|}
\hline Wood species of sawn lumber & Lumber grades & Construction & Standard & Utility & Below \\
\hline Douglas-fir & $\begin{array}{l}\text { Sample numbers } \\
\text { Average } \mathrm{DMOE}_{\mathrm{v}}(\mathrm{MPa}) \\
\text { Average } \mathrm{DMOE}_{\mathrm{t}}(\mathrm{MPa}) \\
\text { Average MOE }(\mathrm{MPa})\end{array}$ & $\begin{array}{l}16 \\
16591(15)^{\mathrm{a}} \\
14277(11)^{\mathrm{a}} \\
14793(19)^{\mathrm{a}}\end{array}$ & $\begin{array}{l}23 \\
15532(8)^{\mathrm{b}} \\
12924(9)^{\mathrm{b}} \\
13009(10)^{\mathrm{b}}\end{array}$ & $\begin{array}{l}22 \\
14028(10)^{\mathrm{c}} \\
11964(11)^{\mathrm{c}} \\
11834(11)^{\mathrm{c}}\end{array}$ & $\begin{array}{l}99 \\
12497(14)^{\mathrm{d}} \\
11529(14)^{\mathrm{d}} \\
11204(15)^{\mathrm{d}}\end{array}$ \\
\hline Japanese cedar & $\begin{array}{l}\text { Sample numbers } \\
\text { Average } \mathrm{DMOE}_{\mathrm{v}}(\mathrm{MPa}) \\
\text { Average } \mathrm{DMOE}_{\mathrm{t}}(\mathrm{MPa}) \\
\text { Average } \mathrm{MOE}(\mathrm{MPa})\end{array}$ & $\begin{array}{l}34 \\
11935(14)^{\mathrm{a}} \\
11285(15)^{\mathrm{a}} \\
11403(14)^{\mathrm{a}}\end{array}$ & $\begin{array}{l}20 \\
11550(21)^{\mathrm{b}} \\
10582(19)^{\mathrm{b}} \\
10408(17)^{\mathrm{b}}\end{array}$ & $\begin{array}{l}20 \\
10275(20)^{\mathrm{c}} \\
9439(17)^{\mathrm{c}} \\
9191(16)^{\mathrm{c}}\end{array}$ & $\begin{array}{l}64 \\
9321(27)^{\mathrm{d}} \\
8220(24)^{\mathrm{d}} \\
7898(23)^{\mathrm{d}}\end{array}$ \\
\hline
\end{tabular}

Values in () representing coefficient of variation (\%); a, b, c, and d show significant differences at the 0.05 level by the Tukey test of ANOVA.

construction grade lumber - 16 pieces; (B) standard grade lumber - 23 pieces; (C) utility grade lumber -22 pieces; and (H) below grade lumber - 99 pieces. Analysis of MOE values, according to CNS14631 and using ANOVA (Analysis of Variance) test, indicated significant differences in MOE, between the four grades of lumber.

Consequently, the Japanese cedar sawn lumber was graded according to CNS14631 specifications. The ANOVA results were significantly different (see Table 1).

The results indicated that the DMOEv, DMOEt and MOE values for both Douglas-fir and Japanese cedar lumber showed a decreasing order as follows: construction grade $>$ standard grade $>$ utility grade $>$ below grade. MOE values for the Japanese cedar sawn lumber, which had been classified according to JAS, were special grade lumber $>$ first grade lumber $>$ second grade lumber $>$ third grade lumber [5]. By grading Taiwania cryptomerioides visually, it was found that the higher the grade of lumber, the higher the MOE value [6].

\subsection{MOE values for Douglas-fir and Japanese cedar sawn lumber}

The MOE values in static bending for the Douglas-fir sawn lumber were 7262.1-20820.0 MPa, with the average being $11880.0 \mathrm{MPa}$. The analysis showed that DMOEv, which was determined by the transmission speed of ultrasonic waves, was higher than both DMOEt, determined using the transverse vibration test, and MOE; DMOEv was $12.6 \%$ higher than DMOEt and $14.2 \%$ higher than MOE. In comparison to DMOEv, DMOEt and MOE were similar; DMOEt was $1.4 \%$ higher than MOE.

The MOE values of the Japanese cedar sawn lumber were 7979.3-16417.1 MPa, the average being 10547.3 MPa. The analysis showed that DMOEv was higher than both DMOEt and MOE, with DMOEv being 5.4\% higher than DMOEt and 6.4\% higher than MOE. DMOEt and MOE were similar, with DMOEt being $0.89 \%$ higher than MOE.

The values of DMOEv and DMOEt are higher than those of MOE. This phenomenon is because wood is a viscous elastic and highly impact-absorbent material. In the vibration of a wood specimen, the restored elastic force is proportional to the displacement and the dissipative force is proportional to the velocity. Therefore, when force is applied for a short time, the material shows a solid elastic behavior while, with longer applications of force, its behavior is equal to that of a viscous liquid. This behavior is more evident in static bending test than in ultrasonic methods. Thus, the modulus of elasticity determined by the ultrasonic method is usually greater than that obtained from the static bending method [7].

Wang et al. [8] selected jack pine and red pine for testing, using stress waves transmission speed, transverse vibration and static bending methods. They found that MOEsw, which had been determined by the stress waves transmission speed test, was higher than MOEt, which had been determined by transverse vibration and MOE. In the case of jack pine, MOEsw was $24.7 \%$ higher than MOEt and $21.6 \%$ higher than MOE, while for red pine, MOEsw was $18.8 \%$ higher than MOEt and 21.6\% higher than MOE. Overall, MOEt and MOE were close, with MOEt being about 7\% higher than MOE; Burdzik and Nkwera [9] pointed out that MOEt was around 5\% higher than MOE.

Our study concurred with these findings, as we found that DMOEv was higher than both DMOEt and MOE, which were close to each other.

\subsection{The correlation between wood density and MOE}

The DMOEv, DMOEt, MOE values, together with the wood density $\left(r_{\mathrm{u}}\right)$ levels of Douglas-fir and Japanese cedar sawn lumber, were analyzed using linear regression analysis (Table 2). It was found that as the wood density increased, the values of DMOEv, DMOEt and MOE also increased. Although these results were significant at the 0.01 level, the $R^{2}$ values of the regression analysis were not high. Wang and Lin [5] pointed out that the $R^{2}$ values of linear regression analysis of MOE, MOR and wood density of Japanese cedar were between 0.314 and 0.624. Burdzik and Nkwera [9] also pointed out that use of wood density alone could not accurately forecast MOE and MOR. Wood density is only one factor used in forecasting the MOE and MOR of lumber.

\subsection{The correlation of DMOEv, DMOEt and MOE}

We found that DMOEv and DMOEt were usually higher than MOE, and could be used as a basis of forecast- 
Table 2

Correlation among $r_{\mathrm{u}}$ (wood density), DMOE $\mathrm{v}, \mathrm{DMOE}_{\mathrm{t}}$ and MOE, analyzed by linear regression $(Y=A X+B)$ formulae for Douglas-fir and Japanese cedar sawn lumber

\begin{tabular}{|c|c|c|c|c|c|c|}
\hline Wood species of sawn lumber & $Y$ & $X$ & $A$ & $B$ & $R^{2}$ & $F$ values \\
\hline \multirow[t]{3}{*}{ Douglas-fir } & $\mathrm{DMOE}_{\mathrm{v}}$ & $r_{\mathrm{u}}$ & 35249 & -4703 & 0.42 & $118^{* *}$ \\
\hline & $\mathrm{DMOE}_{\mathrm{t}}$ & $r_{\mathrm{u}}$ & 27689 & -2300 & 0.34 & $82^{* *}$ \\
\hline & MOE & $r_{\mathrm{u}}$ & 34245 & -5868 & 0.34 & $83^{* *}$ \\
\hline \multirow[t]{3}{*}{ Japanese cedar } & $\mathrm{DMOE}_{\mathrm{v}}$ & $r_{\mathrm{u}}$ & 24634 & 63.6 & 0.40 & $90^{* *}$ \\
\hline & $\mathrm{DMOE}_{\mathrm{t}}$ & $r_{\mathrm{u}}$ & 19351 & 663.9 & 0.38 & $79^{* *}$ \\
\hline & MOE & $r_{\mathrm{u}}$ & 15254 & 2681 & 0.27 & $51^{* *}$ \\
\hline
\end{tabular}

Table 3

Correlation among $\mathrm{DMOE}_{\mathrm{v}}, \mathrm{DMOE}_{\mathrm{t}}$ and MOE, analyzed by linear regression $(Y=A X+B)$ formulae for Douglas-fir and Japanese cedar sawn lumber

\begin{tabular}{|c|c|c|c|c|c|c|}
\hline Wood species of sawn lumber & $Y$ & $X$ & $A$ & $B$ & $R^{2}$ & $F$ values \\
\hline Douglas-fir & $\begin{array}{l}\mathrm{DMOE}_{\mathrm{t}} \\
\text { MOE } \\
\text { MOE }\end{array}$ & $\begin{array}{l}\mathrm{DMOE}_{\mathrm{v}} \\
\mathrm{DMOE}_{\mathrm{v}} \\
\mathrm{DMOE}_{\mathrm{t}}\end{array}$ & $\begin{array}{l}0.814 \\
0.971 \\
1.107\end{array}$ & $\begin{array}{r}-365 \\
-1072 \\
47\end{array}$ & $\begin{array}{l}0.86 \\
0.80 \\
0.83\end{array}$ & $\begin{array}{l}958^{* *} \\
639^{* *} \\
657^{* *}\end{array}$ \\
\hline Japanese cedar & $\begin{array}{l}\mathrm{DMOE}_{\mathrm{t}} \\
\mathrm{MOE} \\
\mathrm{MOE}\end{array}$ & $\begin{array}{l}\mathrm{DMOE}_{\mathrm{v}} \\
\mathrm{DMOE}_{\mathrm{v}} \\
\mathrm{DMOE}_{\mathrm{t}}\end{array}$ & $\begin{array}{l}0.782 \\
0.625 \\
0.808\end{array}$ & $\begin{array}{l}1874 \\
3532 \\
1947\end{array}$ & $\begin{array}{l}0.73 \\
0.54 \\
0.80\end{array}$ & $\begin{array}{l}365^{* *} \\
159^{* *} \\
550^{* *}\end{array}$ \\
\hline
\end{tabular}

ing the properties of lumber. We already knew that there was a high correlation between DMOEv, DMOEt and MOE [5,8-14]. The results of the analysis of DMOEv, DMOEt and MOE, using linear regression analysis, are tabulated in Table 3.

Based on the above results, we knew that DMOEv and DMOEt were both dynamic and so were highly correlated. There was also a high correlation between the three measurements, DMOEt, DMOEv and MOE, especially between DMOEt and MOE, whose $R^{2}$ values were 0.83 and 0.80 , respectively and that this was a better way to determine MOE (Figs. 1 and 2). These results were similar to the findings of Wang et al. [8] and Wang and Lin [5].

Burdzik and Nkwera [9] selected Eucalyptus grandis to determine DMOEt and MOE; the $R^{2}$ value was 0.813 . Marra et al. [11] tested western hemlock, with an $R^{2}$ value of 0.92. Ross and Pellerin [12] tested Douglas-fir, with an $R^{2}$ value of 0.98 and Green and McDonald $[13,14]$ selected red oak and red maple to test, the $R^{2}$ values being 0.92 and 0.85 , respectively. Erikson et al. [15] determined the DMOEt and MOE of grand fir and lodgepole pine and determined the $R^{2}$ values as 0.87 and 0.89 , respectively.

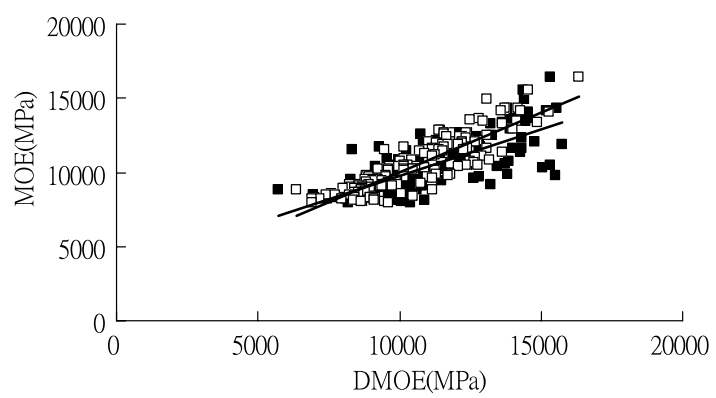

Fig. 1. The relationship between DMOE and MOE for Japanese cedar sawn lumber. $\mathbf{~ - ~ D M O E v ~ f o r ~ J a p a n e s e ~ c e d a r ~ s a w n ~ l u m b e r ; ~} \square$ : DMOEt for Japanese cedar sawn lumber.
As can be seen from the above information, it may be feasible to evaluate the properties of lumber via DMOEt, DMOEv and MOE. Therefore, this type of nondestructive evaluation could also be used to determine the economic mechanical stress ratings for glulam laminas.

\subsection{Static bending properties of Douglas-fir and Japanese cedar glulam}

Wang and Chang [16] pointed out that the disposal of lamina was based on the bending stiffness of the laminate $\left(e_{\mathrm{j}} I_{\mathrm{j}}=\right.$ the bending stiffness of the $j$ lamina layer). This means that the bending stiffness of glulam was the sum of the bending stiffness of every lamina under the non-glue layers, shown as formula (1) [16,17]:

$E_{\mathrm{b}} I=\sum e_{j} I_{j}$,

where

$E_{\mathrm{b}} \quad$ MOE of glulam;

I section moment of inertia of glulam;

$e_{\mathrm{j}}, I_{\mathrm{j}} \quad \mathrm{MOE}$ and section moment of inertia of the $j$ lamina.

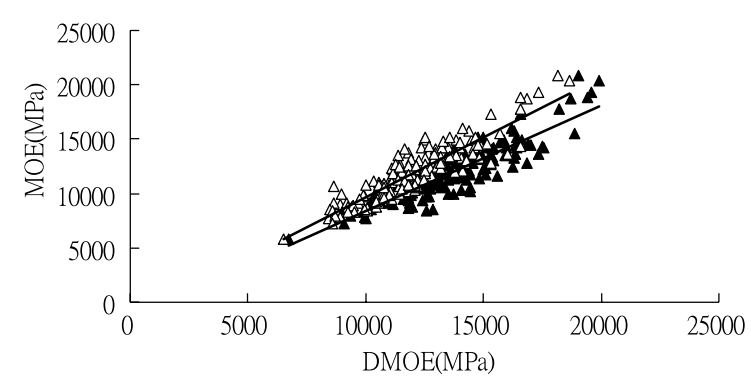

Fig. 2. The relationship between DMOE and MOE for Douglas-fir sawn lumber. $\boldsymbol{\Delta}$ : DMOEv for Douglas-fir sawn lumber; $\triangle$ : DMOEt for Douglas-fir sawn lumber. 
a

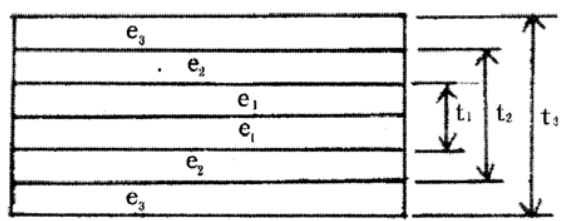

non-glue layer

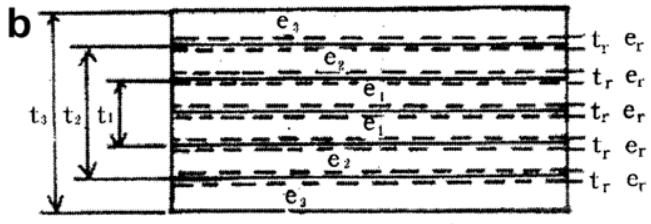

have glue layer

Fig. 3. Longitudinal section of glulam. $e_{\mathrm{r}}$ : the MOE of each lamina under free conditions; $t_{\mathrm{r}}$ : the thickness of the glue-layer.

If we consider that the effect of the existence of the glue layers, the bending stiffness of glulam $E_{\mathrm{b}} I$ is the sum of the bending stiffness of every lamina and every glue layer:

$E_{\mathrm{b}} I=\sum\left(e_{j} I_{j}+e_{r j} I_{r j}\right)$

where $e_{\mathrm{rj}}, I_{\mathrm{rj}}$ : MOE and section moment of inertia of the $j$ layer of the glue line.

There are six lamina in our test glulam as shown in Fig. 3. If a non-glue layer exists, the $E_{\mathrm{b}}$ is as follows:

$E_{\mathrm{b}}=\frac{\sum e_{j} I_{j}}{I}=e_{3}-\left(e_{3}-e_{2}\right) \frac{t_{2}^{3}}{t_{3}^{3}}-\left(e_{2}-e_{1}\right) \frac{t_{1}^{3}}{t_{3}^{3}}$.

If the glue layer exists, then $E_{\mathrm{b}}$ is

$$
\begin{aligned}
E_{\mathrm{b}} & =e_{3}-\left(e_{3}-e_{2}\right) \frac{t_{2}^{3}}{t_{3}^{3}}-\left(e_{2}-e_{1}\right) \frac{t_{1}^{3}}{t_{3}^{3}}+3 \operatorname{tr}\left(2 e_{r}-e_{3}-e_{2}\right) \frac{t_{2}^{3}}{t_{3}^{3}} \\
& +3 t_{r}\left(2 e_{r}-e_{2}-e_{1}\right) \frac{t_{1}^{3}}{t_{3}^{3}} .
\end{aligned}
$$

Laminas of Douglas-fir, numbering 160, were graded into four groups for this study via formula (4). The heterogeneously graded combined group, GDI (MOE of $e_{3}$ :
16.7 GPa; MOE of $e_{1}$ and $e_{2}: 12.7 \mathrm{GPa}$ ), and homogeneously graded combined group, GD3H (MOE: 13.7 GPa), GD2H (MOE: 12.7 GPa), and GD1H (MOE: $9.8 \mathrm{GPa}$ ), respectively. Laminas of Japanese cedar, numbering 138, were graded into four groups for this study via formula (4). The heterogeneously graded combined group, GJI (MOE of $e_{3}: 13.7 \mathrm{GPa}$; $\mathrm{MOE}$ of $e_{1}$ and $e_{2}$ : $9.3 \mathrm{GPa}$ ), and homogeneously graded combined group, GJ3H (MOE: 11.8 GPa), GJ2H (MOE: $10.8 \mathrm{GPa}$ ), and GJ1H (MOE: $9.3 \mathrm{GPa}$ ), respectively. The $E_{\mathrm{b}(\mathrm{sp})}$ of the glulam, calculated using formula (4), is shown in Table 4. The thickness of the glue-layer (RF) of $0.0281 \mathrm{~cm}$ and its MOE of $17042.2 \mathrm{MPa}$ were substituted in formula $(4)[17,18]$.

The $E_{\mathrm{b}(\mathrm{sc})}$ values, determined by the three-point-loading test, are shown in Table 4 . We found that the coefficient of variation $(\mathrm{CV})$ values of the glulam were all lower than those of the lamina.

In comparing $E_{\mathrm{b}(\mathrm{sp})}$ (values calculated from formula (4)) to $E_{\mathrm{b}(\mathrm{sc})}$, we found that as the $E_{\mathrm{b}(\mathrm{sp})}$ increased, the $E_{\mathrm{b}(\mathrm{sc})}$ also increased. Examination via the $F$-test showed that it was significant under a level of 0.01 . In addition, $E_{\mathrm{b}(\mathrm{sp})}$ values were all higher than $E_{\mathrm{b}(\mathrm{sc})}$ values; for Douglas-fir glulam they were $1-17 \%$ higher, and for Japanese cedar glulam they were $1-14 \%$ higher. This is because the tested glulams were subjected to bending stresses acting in combination with shearing stresses during bending test. However, the influence of shearing strain resulted from shearing stresses was not considered in the calculation of $E_{\mathrm{b}(\mathrm{sp})}$ using formula (4). $E_{\mathrm{b}(\mathrm{sp})}$ and $E_{\mathrm{b}(\mathrm{sc})}$ were also analyzed using regression analysis and a correlation was found between the two (Table 5).

DMOEvl of the glulam laminate was investigated using the transmission speed of ultrasonic waves. The comparison between DMOEvl and DMOEv showed no significant differences. A possible reason for this is that the glulam laminations were restricted by the layers of glue, so the properties of the glulam did not change through processing with glue and high frequency induction heating pressure.

Table 4

\begin{tabular}{|c|c|c|c|c|c|c|c|c|c|}
\hline \multirow[t]{2}{*}{ Glulams } & & \multicolumn{2}{|c|}{$E_{\mathrm{b}(\mathrm{sp})}\left(\times 10^{3} \mathrm{MPa}\right)$} & \multicolumn{2}{|c|}{$E_{\mathrm{b}(\mathrm{sc})}\left(\times 10^{3} \mathrm{MPa}\right)$} & \multicolumn{2}{|c|}{ MOR (MPa) } & \multicolumn{2}{|l|}{$\sigma(\mathrm{MPa})$} \\
\hline & & Average & CV $(\%)$ & Average & CV $(\%)$ & Average & CV $(\%)$ & Average & $\mathrm{CV}(\%)$ \\
\hline \multirow[t]{3}{*}{ Douglas-fir } & GDI group & 16.85 & 2.0 & 15.54 & 6.0 & 65.6 & 7.3 & 56.9 & 8.0 \\
\hline & GD2H group & 13.68 & 6.0 & 12.43 & 5.0 & 49.3 & 15.6 & 42.5 & 15.9 \\
\hline & GD1H group & 10.39 & 2.0 & 9.93 & 7.0 & 37.2 & 18.7 & 30.5 & 8.6 \\
\hline \multirow[t]{2}{*}{ Japanese cedar } & GJI group & 13.01 & 0.02 & 12.35 & 0.03 & 61.9 & 2.7 & 54.2 & 8.4 \\
\hline & GJ1H group & 10.02 & 0.00 & 10.00 & 0.02 & 48.3 & 12.8 & 38.4 & 12.8 \\
\hline
\end{tabular}

The modulus of elasticity $\left(E_{\mathrm{b}(\mathrm{sp})}\right)$ and $\left(E_{\mathrm{b}(\mathrm{sc})}\right)$ values of glulam

$E_{\mathrm{b}(\mathrm{sp})}$ : was calculated through formula $(4) ; E_{\mathrm{b}(\mathrm{sc})}$ : was determined through the three-point-loading test; $\mathrm{CV}(\%)$ : coefficient of variation.

GDI group: heterogeneously graded combined group (MOE of $e_{3}: 16.7 \mathrm{GPa}$; MOE of $e_{1}$ and $e_{2}: 12.7 \mathrm{GPa}$ ).

GD3H group, GD2H group, and GD1H group: homogeneously graded combined group, GD3H (MOE: 13.7 GPa), GD2H (MOE: 12.7 GPa), and GD1H (MOE: $9.8 \mathrm{GPa})$, respectively.

GJI group: heterogeneously graded combined group (MOE of $e_{3}: 13.7 \mathrm{GPa}$; $\mathrm{MOE}$ of $e_{1}$ and $e_{2}: 9.3 \mathrm{GPa}$ ).

GJ3H group, GJ2H group, and GJ1H group: homogeneously graded combined group, GJ3H (MOE: $11.8 \mathrm{GPa})$, GJ2H (MOE: $10.8 \mathrm{GPa})$, and GJ1H (MOE: $9.3 \mathrm{GPa}$ ), respectively. 
Table 5

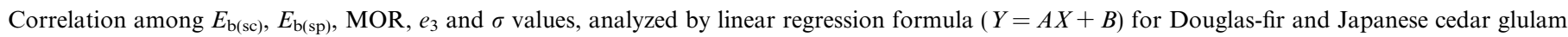

\begin{tabular}{|c|c|c|c|c|c|c|}
\hline Wood species of glulam & $Y$ & $X$ & $A$ & $B$ & $R^{2}$ & $F$ value \\
\hline Douglas-fir & $E_{\mathrm{b}(\mathrm{sc})}$ & $E_{\mathrm{b}(\mathrm{sp})}$ & 0.864 & 1039 & 0.82 & $115^{* *}$ \\
\hline Japanese cedar & $E_{\mathrm{b}(\mathrm{sc})}$ & $E_{\mathrm{b}(\mathrm{sp})}$ & 0.758 & 2300 & 0.75 & $57^{* *}$ \\
\hline Both Douglas-fir and Japanese cedar & $E_{\mathrm{b}(\mathrm{sc})}$ & $E_{\mathrm{b}(\mathrm{sp})}$ & 0.846 & 1272 & 0.83 & $223^{* *}$ \\
\hline Douglas-fir & MOR & $E_{\mathrm{b}(\mathrm{sc})}$ & 0.0046 & -7.98 & 0.65 & $46^{* *}$ \\
\hline Japanese cedar & MOR & $E_{\mathrm{b}(\mathrm{sc})}$ & 0.0044 & 7.98 & 0.44 & $15^{* *}$ \\
\hline Both Douglas-fir and Japanese cedar & MOR & $E_{\mathrm{b}(\mathrm{sc})}$ & 0.003 & 13.20 & 0.32 & $21^{* *}$ \\
\hline Douglas-fir & $E_{\mathrm{b}(\mathrm{sc})}$ & $e_{3}$ & 0.071 & 2731 & 0.79 & $92^{* *}$ \\
\hline Japanese cedar & $E_{\mathrm{b}(\mathrm{sc})}$ & $e_{3}$ & 0.055 & 4516 & 0.85 & $103^{* *}$ \\
\hline Both Douglas-fir and Japanese cedar & $E_{\mathrm{b}(\mathrm{sc})}$ & $e_{3}$ & 0.691 & 3084 & 0.81 & $197^{* *}$ \\
\hline Both Douglas-fir and Japanese cedar & MOR & $\sigma$ & 1.08 & 5.11 & 0.95 & $801^{* *}$ \\
\hline
\end{tabular}

The static bending strength (MOR) of Douglas-fir and Japanese cedar glulam was shown in Table 4.

The relationship between MOR and $E_{\mathrm{b}(\mathrm{sc})}$, indicated by linear regression formulae, were also shown in Table 5.

Consider the stiffness properties of individual lamina, the bending stress $(\sigma)$ in the outermost lamina of a glulam can be evaluated from the theory of bending for composite beam as [19-21]

$\sigma=\frac{M E y}{\sum\left(E_{i} I_{i}\right)}$,

where $M$ is the bending moment, $E$ is the MOE of the outmost lamina, $y$ is the distance from the effective neutral axis to the outer surface of the glulam.

In addition, the values of $\sum\left(E_{j} I_{j}\right)$ were calculated from formula (4). The $\sigma$ values of glulam calculated from formula (5) were shown in Table. 4. In comparing $\sigma$ to MOR, it was found that as the $\sigma$ increased, the MOR also increased (Fig. 4), and the relationship could be represented by positive linear regression formula (Table 5). Examination via the $F$-test showed that it was significant under a level of 0.01 .

\subsection{The effect of the lamina configuration on glulam MOE}

It was found that the $E_{\mathrm{b}(\mathrm{sc})}$ of glulam increased as the MOE of the outside layers of lamina $\left(e_{3}\right)$ increased (Fig. 5). The correlation regression formula is shown in

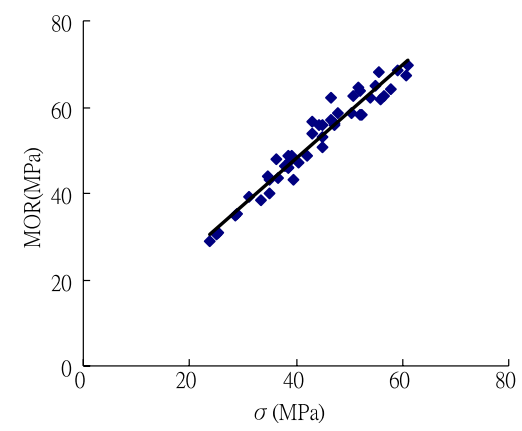

Fig. 4. The relationship between MOR and $\sigma$ for Douglas-fir and Japanese cedar glulam. $\bullet$ : Douglas-fir and Japanese cedar glulam; $\sigma$ : the bending stress calculated from formula (5).
Table 5. We also considered the effect of the differences in MOE of the outside and inside layers of lamina $\left(e_{3}-e_{1}\right)$ to the whole glulam. It was discovered that as the differences in $e_{3}-e_{1}$ values, between the outside and inside layers of lamina increased, the $E_{\mathrm{b}(\mathrm{sc})}$ of the glulam also increased. However, if the difference exceeded a certain limit, the $E_{\mathrm{b}(\mathrm{sc})}$ tended to decrease. In this study we found that if the difference in MOE values between the outside and inside layers of lamina $\left(e_{3}-e_{1}\right)$ was over $2940 \mathrm{MPa}$, the $E_{\mathrm{b}(\mathrm{sc})}$ of the glulam decreased; this was because when loading, the outside layers could withstand the force and remain intact, while the inside layers could not withstand the horizontal shearing force and were destroyed, decreasing its strength.

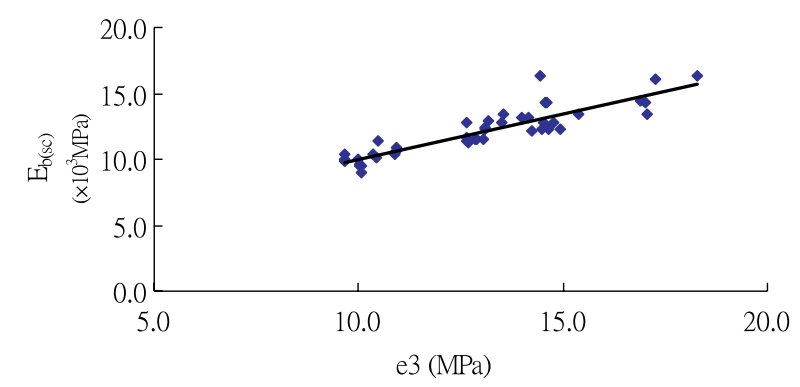

Fig. 5. The relationship between $E_{\mathrm{b}(\mathrm{sc})}$ and $e_{3}$ for Douglas-fir and Japanese cedar glulam. : Douglas-fir and Japanese cedar glulam; $e_{3}$ : MOE of the outside layers of lamina.

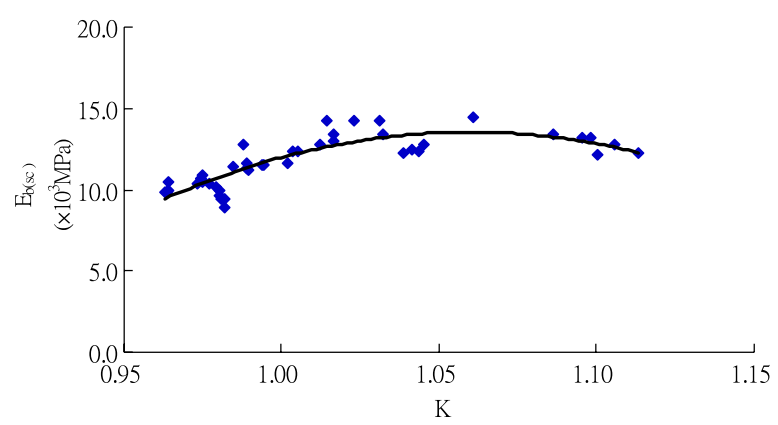

Fig. 6. The relationship between $E_{\mathrm{b}(\mathrm{sc})}$ and $K$ value for Douglas-fir and Japanese cedar glulam. $\bullet$ : Douglas-fir and Japanese cedar glulam; $K: e_{3} /$ $E_{\mathrm{b}(\mathrm{sc})}$. 
Table 6

Correlation among $E_{\mathrm{b}(\mathrm{sc})}$ and $K$ values, analyzed by regression formula $\left(Y=A X^{2}+B X+C\right)$ for Douglas-fir and Japanese cedar glulam

\begin{tabular}{llllllll}
\hline Wood species of glulam & $Y$ & $X$ & $A$ & $B$ & $C$ & $R^{2}$ \\
\hline Both Douglas-fir and Japanese cedar & $E_{\mathrm{b}(\mathrm{sc})}$ & $K$ & -437527 & 927373 & -477863 & 0.78 & $69^{* *}$ \\
\hline
\end{tabular}

$K: e_{3} / E_{\mathrm{b}(\mathrm{sc})}$.

Because the $E_{\mathrm{b}(\mathrm{sc})}$ of the glulam was influenced by the MOE value of the outside layers of lamina $\left(e_{3}\right)$, the specific value of $e_{3} / E_{\mathrm{b}(\mathrm{sc})}$, as the influencing index of disposal $(K)$, was used to confer its influence on the $E_{\mathrm{b}(\mathrm{sc})}$ of glulam. Fig. 6 shows that the $E_{\mathrm{b}(\mathrm{sc})}$ values of the glulam are in compliance with the $K$ values. This relationship can also be seen in Table 6.

\section{Conclusions}

Based on the experimental work conducted in this study, the following conclusions can be drawn.

1. The dynamic modulus of elasticity of Douglas-fir and Japanese cedar sawn lumber increased when the rating class, based on CNS14631specifications, was higher.

2. The DMOEv values of sawn lumber were higher than those of DMOEt and MOE. Thus, the transverse vibration test is a better nondestructive method of evaluating sawn lumber.

3. The different configurations of the lamina within glulam can, therefore, be used to fabricate glulams with different grades of bending strengths.

4. The $E_{\mathrm{b}}$ of the glulam increased as the MOE of the outside lamina increased. If the difference in the $\left(e_{3}-e_{1}\right)$ values, between the outside and the inside layers of lamina increased, the $E_{\mathrm{b}(\mathrm{sc})}$ of glulam also increased.

5. Because of glulam lamina restrictions, the average value of glulam $E_{\mathrm{b}(\mathrm{sp})}$ is approximately $6 \%$ higher than that of its $E_{\mathrm{b}(\mathrm{sc})}$.

\section{Acknowledgment}

The authors thank the National Science Council of ROC for the financial support under NSC91-2313-B-002396.

\section{References}

[1] Sobue N. Measuring method of the strength related factors. Wood Indus 1992;47:13-9.

[2] Iijima Y. Wood-base material wood science and utilization technique III large scale wooden structure. In: Japan Wood Research Society, published, 1993. p. 23-62.
[3] Galligan WL, Snodgrass DV, Crow GW. Machine stress rating: Practical concerns for lumber producers. FPL-GTR-7, USDA Forest Serv., Forest Prod. Lab., Madison, Wis., 1997.

[4] Yamada M, Takada M, Sano A. Fire-resistance performance of structural LVL (4). In: Abstracts of the 51st annual meeting of the Japan Wood Research Society, 2001. p. 425.

[5] Wang SY, Lin SH. Effect of plantation spacing with quality of visually graded limber and mechanical properties of Taiwan-growth Japanese cedar. Mokuzai Gakkaishi 1996;42(5):435-44.

[6] Hsu KP, Wang SY. Effects of different spacing distance on wood property of Taiwania Cyptomerioides. In: Abstracts of the 2002 annual meeting of the Chinese forestry association, 2002, p. 335-50.

[7] Halabe UB, Bidigalu GM, Gangarao HVS, Ross RJ. Nondestructive evaluation of green wood using stress wave and transverse vibration techniques. Mater Eval 1997;55(9):1013-8.

[8] Wang X, Ross RJ, Mattson JA, Erickson JR, Forsman JW, Geskse EA, et al. Nondestructive evaluation techniques for assessing modulus of elasticity and stiffness of small-diameter logs. Forest Prod J 2002;52(2):79-85.

[9] Burdzik WMG, Nkwera PD. Transverse vibration tests for prediction of stiffness and strength properties of full size Eucalyptus grandis. Forest Prod J 2002;52(6):63-7.

[10] Pellerin RF. A vibrational approach to nondestructive testing of structure lumber. Forest Prod J 1965;15(3):93-101.

[11] Marra GG, Pellerin RF, Galligan WL. Non-destructive determination of wood strength and elasticity by vibration. Wood Wood Prod 1966;24(10):460-6.

[12] Ross RJ, Pellerin RF. Stress wave evaluation of green material: preliminary results using dimension lumber. Forest Prod J 1991;41(6):57-9.

[13] Green DW, McDonald KA. Investigation of the mechanical properties of red oak 2 by 4's. Wood Fiber Sci 1993;25(1):35-45.

[14] Green DW, McDonald KA. Mechanical properties of red maple structure lumber. Wood Fiber Sci 1993;25(4):365-74.

[15] Erikson RG, Gorman TM, Green DW, Graham D. Mechanical grading of lumber sawn from small-diameter lodgepole pine, ponderosa pine, and grand fir trees from northern Idaho. Forest Prod J 2000;50(7/8):59-65.

[16] Wang SY, Chang T. Studies on the flexural properties of laminated beams with different wood species (1) Bending modulus of elasticity. Q J Chin Forest 1978;11(1):43-52.

[17] Okuma M. Studies on the mechanical properties of plywood. Bull Tokyo Univ Forest 1967;63:1-60.

[18] Wang SY, Cho JL. Studies on the dynamic and acoustic behaviors of wood (III). Forest Prod Indus 1985;4(3):2-26.

[19] Curry WT, Hearmon RFS. The strength properties of plywood. In: The strength properties of Timber. London, UK: MTP Construction; 1974. p. 6.177-208.

[20] Gere JM, Timoshenko SP. Mechanics of materials. 4th ed. Boston, MA: PWS Publishing Co; 1997. p. 391-6.

[21] Dansoh AB, Koizumi A, Hirai T. Bending strength and stiffness of glued butt-jointed glulam. Forest Prod J 2004;54(9):40-4. 